\title{
Timeless lessons from the past and present leaders of cardiothoracic surgery part 1: Professional accomplishment
}

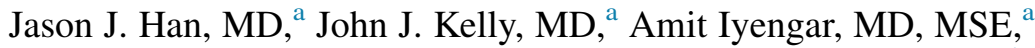
William L. Patrick, MD, ${ }^{a}$ and Ibrahim Sultan, MD, FACS, FACC ${ }^{b}$

From the a Division of Cardiothoracic Surgery, Department of Surgery, Hospital of the University of Pennsylvania, Philadelphia, Pa; and the ${ }^{\mathrm{b}}$ Department of Cardiothoracic Surgery, University of Pittsburgh, Pittsburgh, Pa.

Disclosures: Authors have nothing to disclose with regard to commercial support.

Received for publication April 28, 2019; revisions received June 10, 2019; accepted for publication June 13, 2019; available ahead of print July 16, 2019.

Address for reprints: Jason J. Han, MD, Division of Cardiothoracic Surgery, Department of Surgery, Hospital of the University of Pennsylvania, 3400 Spruce St, 6 Silverstein Pavilion, Philadelphia, PA (E-mail: Jason.Han@ uphs.upenn.edu).

J Thorac Cardiovasc Surg 2019;158:1602-6

$0022-5223 / \$ 36.00$

Copyright (c) 2019 by The American Association for Thoracic Surgery

https://doi.org/10.1016/j.jtcvs.2019.06.022

Founded in 1917, The American Association for Thoracic Surgery (AATS) has served as the nucleus of our specialty, facilitating not only the exchange of knowledge, but also values that define our professional standards. True to the AATS core values of leadership, education, and mentorship, the leaders have not only been tasked with overseeing the organization but also imparting their wisdom to those who seek to emulate their character and aspire to reach their heights. Each year, these messages are delivered in the form of the presidential address, which is read at the AATS annual meeting and subsequently published in the Journal of Thoracic and Cardiovascular Surgery. Synthesized from a lifetime of operating and learning to navigate both personal and career-related challenges, these words comprise an invaluable resource for those in our field.

The central assumption in sharing the messages of former AATS presidents is that their legacy of wisdom, integrity, and leadership, as well as tales of cognitive and technical prowess, should serve invaluable in the motivation and guidance of young surgeons in cardiothoracic surgery (CTS). Thus, as aspiring surgeons, we should be exposed to these lessons early in our training process to build a foundation for ongoing reflection and self-refinement. The objective of this article is to highlight and analyze lessons imparted to young surgeons by those with the most aspirational careers.

\section{METHODS}

Twenty-eight former AATS presidents were selected based on the availability of their interviews in the book In the Words of the Presidents. ${ }^{1}$ The corresponding transcribed presidential address was identified. ${ }^{2-17}$ Published addresses were not found for 3 of the former AATS presidents: W. Gerald Austen, D. Craig Miller, and Hartzell V. Schaff. A videorecording of Schaff's address was found online. ${ }^{18}$

Qualitative analysis was performed by 4 integrated CTS resident physicians who independently read the presidential addresses and interviews,

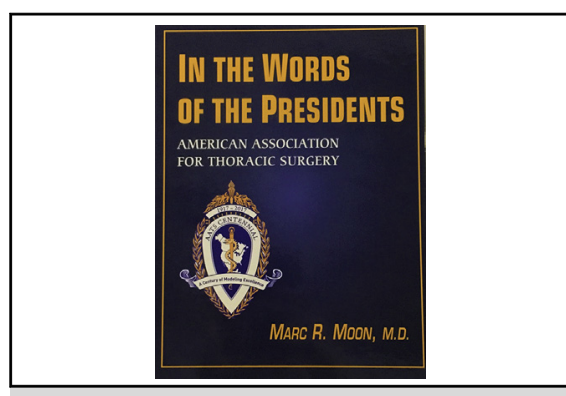

One of the central texts: In the Words of the Presidents by Marc R. Moon.

Central Message

Professional excellence is a core component of a successful career in cardiothoracic surgery. We present collective wisdom from leaders in the field for aspiring surgeons.

identified major themes relevant to young surgeons, and compiled salient quotations. The 4 resident physicians then discussed overarching themes and the organization of the manuscript. Seven major themes were identified: the attainment of surgical excellence, mentorship, scholarship and innovation, displaying humanism and the doctor-patient relationship, well-being and work-life balance, leadership, and the future of CTS and education of surgeons. Based on this thematic analysis, it was decided to organize the content into a 2-part series for publication: professional accomplishment: achieving surgical excellence and the importance of mentorship, scholarship, and innovation; and character development: displaying humanism, maintaining well-being and life balance, fostering leadership ability, and the future of CTS and education of surgeons. Each article consists of 2 sections: a presentation of salient quotations from former AATS presidents followed by a brief reflection by the 4 resident physician authors identifying major takeaway messages for trainees. Finally, an attending surgeon who recently finished training and reviewed the drafts and provides reflections and commentary.

Here we present the first article of the 2-part series: Professional accomplishment. Table 1 lists the former AATS presidents included in this analysis and relevant themes addressed (ie, attaining surgical excellence, the role of mentorship, or the importance of scholarship and innovation).

\section{On Achieving Surgical Excellence}

For surgeons, there is no better measure of excellence than technical competence. "Clearly our core mission," according to Gardner, "is the accomplishment of excellent surgical care." This sentiment was echoed by Cohn, ${ }^{3}$ who described "what the [cardiothoracic] surgeon of the twenty-first century ought to be" through 11 essential qualities. First on his list: "An excellent surgeon.",

Several former AATS presidents described the essence of surgical excellence. According to Sugarbaker, ${ }^{4}$ "it is performing a task consistently, as close to the ideal as possible." For Kron, ${ }^{5}$ technical surgery "is a 
juxtaposition of one's hands and brain. It requires working with a team [and] being able to work with tension and the various emotions caused by uncertain situations." David ${ }^{6}$ compared CTS to woodcarving, because a surgeon's outcomes, like those of a skilled craftsman, "depend on knowledge, judgment, dexterity, caring, and attention to detail."

True excellence is defined not only by rote technical skill, but also by cognitive ability. "I know many surgeons whose hands work just fine but they aren't very good surgeons," said Smith. ${ }^{7} \mathrm{He}$ argued that in addition to technical skill, surgical excellence also involves composure, curiosity, confidence, and innovation. "It is those more personal qualities when put together with manual dexterity," concluded Smith, "that defines the master surgeon" Similarly, Patterson ${ }^{8}$ believed that "...what we do in surgery is actually pretty simple. Pronation, supination, traction and countertraction... but it is the implementation of those basic simple skills in a complex sequence that requires forethought and training." According to Casteneda, an "aesthetic appreciation of 3-dimensional space" is required in addition to muscular coordination. "Like a work of art, to achieve perfection, an operation must transcend technique and become an intellectual and aesthetic endeavor." 9

Among the most important insights for young surgeons was a prescription for approaching perfection in the operating room. The most commonly expressed theme was dedication to the craft. "Excellence is not a trait inherited by fortunate individuals," said Sugarbaker. "Rather, it must be achieved and maintained through sustained, purposeful, focused action." 4 This entails "....all of one's conscious attention...exclusively and unrelentingly focused on that physical and intellectual activity." ${ }^{4}$ According to David, "Surgeons who rise above the expected level of competence are highly motivated and have the uncommon ability to concentrate during the performance of surgical procedures." Such young surgeons "excel in knowledge, judgment, and dexterity because every patient they care for is a source of new information..." In the words of Casteneda, "To reach excellence you have to commit a lot of time with an almost fanatical dedication to push the frontiers of knowledge" Austen ${ }^{1}$ also emphasized the importance of absolute dedication. "I never, ever had an alcoholic drink," he admitted, "because I felt that I ought to be prepared to do whatever was necessary 24 hours a day, 7 days a week." Smith ${ }^{7}$ likened aspiring surgeons in our field to climbers of the Himalayas, “...for whom a particular type of daunting goal is worth every step of an arduous journey."

Frequent self-assessment and self-improvement were also identified as essential qualities in the pursuit of excellence. "The best surgeons," said Loop, ${ }^{10}$ "do not forget their mistakes, and they compete mainly with themselves to get better every year." Similarly, David ${ }^{6}$ described how exceptional young surgeons "monitor their own performance obsessively and worry constructively. They worry because they care." Smith ${ }^{7}$ explained that "an important part of success is learning how to fail" and to "come back again even stronger... No one has true confidence who hasn't lost it and gotten it back."

The path to surgical excellence involves passion, perseverance, selfassessment, and self-improvement. Although the journey may be long and arduous, "the joy, teamwork, and friendship in the pursuit of excellence in the operating theater is a unique privilege that very few get to experience," said Kron. "If done well, there is a wonderful result for the surgeon, the team, and most importantly, the patient." 5

\section{On Mentorship}

Mentorship was identified as one of the most critical functions of the CTS community. According to Coselli, ${ }^{11}$ "the collective guidance is irreplaceable." Many of the former AATS presidents attributed a large part of their success to their mentors. "It is readily apparent," said Wallace, ${ }^{12}$ "that it is not what you know but whom you are fortunate enough to know that is important." Similarly, Jonas ${ }^{13}$ argued that "CTS training is still ultimately a mentorship, and there is a fundamental obligation on the part of the mentor to assist the trainee to have a productive and satisfying position at the end of the training process." Whereas most of the advice was directed toward other already-trained surgeons on how to be effective teachers and role models, these lessons were deemed valuable for young surgeons both in learning to choose mentors as well as to serve as mentors themselves as they ascend the ladder.

An ideal mentor was defined as possessing a variety of traits. Primarily, a mentor must be "hands on" and "cannot teach from the office." ${ }^{5}$ Furthermore, the mentor must also have "...a definite interest and take pride of ownership in the career development" of mentees. ${ }^{2}$ This entails patience and dedication, being "...willing to spend additional time and effort..." teaching young surgeons. ${ }^{2}$ More broadly, a mentor should aspire to be a teacher both in and out of the operating room. According to Kron, ${ }^{5}$ true mentorship "is more than just about technical surgery, but about life." This involves conveying to young surgeons the importance of maintaining a work-life balance and taking care of family, friends, and oneself. "Teaching this aspect of humanity," Kron concluded, “...makes us better physicians and surgeons." 5 In this vein, Schaff ${ }^{18}$ found the term mentor, which he defined as "synonymous with counselor, or guide," inadequate. Instead, he implored his audience to "... be a role model," which he defined more holistically "...as the surgeons who by dedication, skill, and character" drew others into this specialty. Of course, for any mentorship to succeed, it cannot be a single-sided relationship and requires active participation by the mentee. Smith ${ }^{7}$ described how a good mentor “...needs to allow you to stumble a few times," so that mentees may learn to recognize their own obstacles, forge their own resilience, and learn to "...take advice and learn by example."

Mentorship is an essential component of CTS. Resident physicians and fellows must seek out those who are not only invested in their mentees and passionate about education, but also, in the words of Casteneda, " "awaken in the student a lifelong desire to learn."

\section{On Scholarship and Innovation}

Many former AATS presidents emphasized the importance of research and scholarly efforts in pursuit of new knowledge and advancement of the field of CTS. This sentiment is aligned with the AATS mission to promote scholarship, innovation, and leadership. Conventional forms of research, such as translational and clinical work, were frequently mentioned. Gardner, ${ }^{2}$ in his 2002 presidential address, discussed his efforts in creating the Scientific Affairs and Government Relations Committee for the AATS, and a decade later, Del Nido ${ }^{14}$ celebrated the successes of the committee in achieving the most CTS representation in history in several National Institutes of Health study sections. For the ideal triple-threat academic surgeon, research is an important pillar in addition to clinical practice and education. Increasingly, the traditional concept of research is becoming more broadly defined, encompassing a wider array of activities. "The second area of the triple threat is usually considered research, but I would prefer to call it scholarship, the concept of promoting knowledge in the specialty..." said Crawford. ${ }^{15}$ "The better word, scholarship, can involve clinical outcomes, basic research, or whatever one thinks is important." 15 Still, others recognized the importance of pursuing efforts outside of the laboratory such as public health, advocacy, and globalization. They called for surgeons at all levels to support innovative efforts in a variety of other avenues to complement and expand clinical work. As Smith ${ }^{7}$ described, "what ultimately acquires an 'innovation' label is hard to forecast and hard to identify during development because progress from the idea is an erratic, accumulating clutter of additional ideas, discoveries, and inventions."

Those pursuing research, scholarship, and innovative efforts are often trapped between opposing forces. Contraction of research funding, pressures of clinical work in an often difficult environment, and the changing landscape of the practice of CTS can make scholarly pursuits seemingly taxing and overly arduous. However, many former AATS presidents emphasized persistence for multiple reasons. First, research is essential the overall promotion of CTS as a field. "The truth," said Lytle, ${ }^{16}$ "is our greatest ally" As an example, he discussed how in the early, rapidly growing era of catheter-based coronary revascularization, it was rigorous 
TABLE 1. Analysis of American Association for Thoracic Surgery presidential addresses and interviews by thematic content

\begin{tabular}{|c|c|c|c|c|c|c|}
\hline \multirow[b]{2}{*}{ President } & \multirow[b]{2}{*}{ President no. } & \multirow[b]{2}{*}{ Year } & \multirow[b]{2}{*}{ Title } & \multicolumn{3}{|c|}{ Themes } \\
\hline & & & & Excellence & Mentorship & Scholarship \\
\hline Austen & 89 & 1988 & $\begin{array}{l}\text { Eight Former Presidents of the AATS. The Boston } \\
\text { Connection* }\end{array}$ & $\mathrm{X}$ & $\mathrm{X}$ & $X$ \\
\hline Castaneda & 74 & 1993 & $\begin{array}{l}\text { The Making of a Cardiothoracic Surgeon: An } \\
\text { Appolonian Quest }\end{array}$ & $\mathrm{X}$ & $\mathrm{X}$ & $\mathrm{X}$ \\
\hline Cohn & 79 & 1998 & $\begin{array}{l}\text { What the Cardiothoracic Surgeon of the 21st century } \\
\text { Ought to Be }\end{array}$ & $\mathrm{X}$ & $\mathrm{X}$ & $\mathrm{X}$ \\
\hline Cooper & 84 & 2003 & Thank You for being a Doctor & & $\mathrm{X}$ & $\mathrm{X}$ \\
\hline Coselli & 96 & 2015 & $\begin{array}{l}\text { Competition: Perspiration to Inspiration. Aut inveniam } \\
\text { viam aut faciam }\end{array}$ & $\mathrm{X}$ & $\mathrm{X}$ & $\mathrm{X}$ \\
\hline Cosgrove & 80 & 1999 & The Innovation Imperative & & & $\mathrm{X}$ \\
\hline Cox & 81 & 2000 & Changing Boundaries & & $\mathrm{X}$ & \\
\hline Crawford & 83 & 2002 & $\begin{array}{l}\text { Thoracic Surgery Education-Responding to a } \\
\text { Changing Environment }\end{array}$ & $\mathrm{X}$ & $\mathrm{X}$ & $\mathrm{X}$ \\
\hline David & 85 & 2004 & For Everything There Is a Season & $\mathrm{X}$ & & \\
\hline del Nido & 95 & 2014 & $\begin{array}{l}\text { Technological Innovation in Cardiothoracic Surgery: A } \\
\text { Pragmatist's Approach }\end{array}$ & & $\mathrm{X}$ & $\mathrm{X}$ \\
\hline Ferguson & 62 & 1981 & The Crisis of Excellence & & & $\mathrm{X}$ \\
\hline Gardner & 82 & 2001 & Our Heritage and Our Future & $\mathrm{X}$ & $\mathrm{X}$ & $\mathrm{X}$ \\
\hline Jonas & 86 & 2006 & $\begin{array}{l}\text { Rewards, Risks, and Responsibilities of Globalization } \\
\text { for the Cardiothoracic Surgeon }\end{array}$ & & $\mathrm{X}$ & \\
\hline Kron & 91 & 2010 & Surgical Mentorship & $\mathrm{X}$ & $\mathrm{X}$ & $\mathrm{X}$ \\
\hline Loop & 78 & 1997 & The First Living and the Last Dying & $\mathrm{X}$ & $\mathrm{X}$ & $\mathrm{X}$ \\
\hline Lytle & 87 & 2006 & Who We Are-Who We Will Be & $\mathrm{X}$ & $\mathrm{X}$ & $\mathrm{X}$ \\
\hline Malm & 66 & 1985 & New York: A Bellwether for Thoracic Surgery & & & $\mathrm{X}$ \\
\hline Miller & 88 & 2007 & Anti-memoirs of Rocinante* & & $\mathrm{X}$ & $\mathrm{X}$ \\
\hline Ochsner & 73 & 1992 & Giants & $\mathrm{X}$ & & $\mathrm{X}$ \\
\hline Patterson & 90 & 2009 & Non Solus - A Leadership Challenge & $\mathrm{X}$ & $\mathrm{X}$ & $\mathrm{X}$ \\
\hline Pearson & 70 & 1989 & Adventures in Surgery & & $\mathrm{X}$ & $\mathrm{X}$ \\
\hline Schaff & 93 & 2012 & $\begin{array}{l}\text { Leadership and Scholarship: Unintended Consequences, } \\
\text { Unexpected Benefits }\end{array}$ & $\mathrm{X}$ & $\mathrm{X}$ & $\mathrm{X}$ \\
\hline Smith & 92 & 2011 & To Model Excellence & $\mathrm{X}$ & $\mathrm{X}$ & $\mathrm{X}$ \\
\hline Spencer & 63 & 1982 & Intellectual Creativity in Thoracic Surgery & $\mathrm{X}$ & $\mathrm{X}$ & $\mathrm{X}$ \\
\hline Spray & 89 & 2008 & The Quality Conundrum & $\mathrm{X}$ & & $\mathrm{X}$ \\
\hline Sugarbaker & 94 & 2013 & $\begin{array}{l}\text { Clarity of Purpose, Focused Attention: The Essence of } \\
\text { Excellence }\end{array}$ & $\mathrm{X}$ & & \\
\hline Waldhausen & 72 & 1991 & The Association at 75: The Challenge of the Future & & $\mathrm{X}$ & $\mathrm{X}$ \\
\hline Wallace & 75 & 1994 & Reflections-Projections! & & $\mathrm{X}$ & \\
\hline
\end{tabular}

*Text unavailable. Thematic content information was gleaned from reference 1 .

research and clinical trial designs that demonstrated the durability and, in some populations, superiority of surgical therapy. ${ }^{16}$ Lytle concluded that "every cardiac surgeon must be an academic surgeon, must be able to understand and to credibly discuss data that relate to the treatment of cardiovascular disease." ${ }^{16}$ Second, the pursuit of scholarly efforts and innovation has direct benefits to the participating individual. Schaff ${ }^{18}$ commented that research helps focus resident physicians during training, encourages development of parallel skills and thought processes, and can provide tools to answer problems that arise later in one's career, citing his own experience with the development of the septal myectomy. Most importantly, scholarship and innovation was deemed imperative because it can directly influence and improve the lives of patients. Del Nido ${ }^{14}$ commented that "the potential reward for these efforts is that your idea may ultimately benefit far more patients than you could by treating them yourself directly." Similarly, Loop ${ }^{10}$ taught us that "the ultimate motivation is to achieve a higher standard," a desire that many CTS trainees hold dear.

Scholarly pursuits cannot come at the expense of clinical expertise, however. In his interview, Cox advised that "if you're an academic it is essential that you are an excellent clinician. If they don't respect you as a surgeon, then they're not going to respect you as a teacher and leader." ${ }^{1}$ However, if 
successfully balanced with clinical duties, research can augment an individual's career and training pathway to ever-rising levels. In concluding his presidential address, Gardner ${ }^{2}$ encouraged young surgeons by emphasizing "that the future is yours for the taking." While "unequivocal surgical competence" is essential, "how else you define yourself professionally and personally is limitless." 2 These words invoke the pioneering spirit that brought many of us to CTS in the first place, and encourage us to never stop pursuing scholarship and innovation as we reach for that ever higher standard.

\section{Our Reflections: How We Perceive These Words Will Influence Us, Both in Training and Career}

From the earliest stages of our CTS training, we are introduced to the triple-threat concept, meaning that one is competent in operating, teaching, and conducting research. This is considered the pinnacle of academic accomplishment, something to which many of us aspire. Yet the road to excellence can seem rather nebulous and daunting for young surgeons who must start by learning the most rudimentary aspects of CTS. The lessons gleaned from the words of the former AATS presidents help illuminate this path and offer a potential roadmap. In our analysis of themes of surgical excellence, mentorship, and scholarship, we identified three major takeaways for trainees:

1. First and foremost, become an excellent technical surgeon through dedication and hard work

With regard to achieving excellence, we have taken to heart one fundamental lesson that appeared time and again: No matter what type of cardiothoracic surgeon one aspires to be, one must primarily be an excellent technician. As young surgical trainees, we are often under pressure to balance multiple duties, which include surgical, scholarly, administrative, and extracurricular pursuits. The messages of the former AATS presidents remind us that no matter how prodigious one's research or how expansive one's network, we are ultimately valued for our abilities to operate and to take care of patients.

No former AATS president emphasized talent as a source of success. Rather, each attributed his own excellence to persistence, deliberate practice, and learning from failures. This is reassuring from our perspective because it reinforces the notion that greatness arises from one's passionate commitment and tireless effort. In our program, we have embraced this principle by fostering a culture of practicing outside of the operating room, which includes sharing ideas and building various simulation models on which to practice at home. The senior residents are very involved in teaching the basics of suturing and tying to junior residents. These initiatives have not only improved our skills, but also our camaraderie.

In addition, reading the words of former AATS presidents reminds us that true excellence lies beyond the purely technical. As young surgeons, we tend to gravitate toward the fast or slick aspects of an operation; however, the true mark of surgical prowess lies in the mind more than in the hands in the form of an intense yet composed, confident yet reflective attitude. This idea was discussed by Kron, ${ }^{5}$ who encouraged young surgeons to visualize what a finished operation should look like rather than focusing on individual stitches. The ability to look at a patient's cardiothoracic problem, envision an intervention, plan an operative strategy, and then implement that procedure is what defines a truly excellent surgeon. It is this more cerebral exercise in addition to mechanical skill that we hope to continue to refine.

2. Seek out mentors you can learn from and be a mentor to those who can learn from you.

Mentorship is an active and rewarding process that can begin at any stage of training. One does not have to wait until the apex of his or her career to positively influence others. Rather, it is a state of mind and a lifelong commitment. At our program, in addition to being mentored by attending surgeons, resident physicians and fellows build equally rewarding relationships by mentoring those who look to us for guidance. The more senior trainees serve as invaluable resources for those more junior in the development of surgical skill, involvement in research projects, and maintaining work-life balance. Another avenue has been for resident physicians and fellows to serve as advisors for the cardiothoracic surgery interest groups at local medical schools, participating in events such as information panels and simulation teaching sessions. This has not only encouraged us to embrace teaching early on as a fundamental component of our busy schedules, but also has led to numerous collaborative research projects.

The former AATS presidents remind us that mentorship is among the few processes where the more one gives, the more one gains. Although it requires time and effort, the former AATS presidents have risen to greatness, not despite, but precisely because they have been influential mentors to many, a tree that arborizes endlessly into a long-lasting legacy.

3. Continue to broaden the definition of scholarship and innovation in CTS.

The former AATS presidents broadened the way we view the role of scholarship in CTS. Many reflected on the early years of CTS, where being scholarly meant conducting basic science research. However, they noted scholarship and innovation have expanded in scope and will continue to expand dramatically as new inventions and ideas emerge. They encourage us to pursue broader ambitions that ultimately advance and promote knowledge within the specialty, and complements patient care within our role as surgeons. We are emboldened by these words to pursue efforts both inside and outside of the laboratory, such as in the realms of public health, advocacy, and globalization. We have begun to experiment with new forms of research in CTS, such as technology, multimedia, and social media as powerful tools for education and recruitment, while still pursuing traditional forms of research as a way of contributing to existing bodies of scholarship within the field. By balancing the traditional and the innovative, we aspire to grow in alignment with the road our mentors have laid out before us.

\section{CONCLUSIONS}

Training in CTS is a technically demanding experience that requires constant reflection and introspection. This series highlights 9 major themes from the words of past and present leaders in the field of CTS that are particularly salient topics for young surgeons. The wisdom shared can be formative during the training process and ought to have an important place in the education of aspiring surgeons.

\section{References}

1. Moon MR. In the Words of the Presidents. Beverly: American Association for Thoracic Surgery; 2017.

2. Gardner TJ. Presidential address: our heritage and our future. J Thorac Cardiovasc Surg. 2002;124:649-54.

3. Cohn LH. What the cardiothoracic surgeon of the twenty-first century ought to be. J Thorac Cardiovasc Surg. 1999;118:581-7. 
4. Sugarbaker DJ. Clarity of purpose, focused attention: the essence of excellence. $J$ Thorac Cardiovasc Surg. 2014;148:764-71.

5. Kron IL. Surgical mentorship. J Thorac Cardiovasc Surg. 2011;142:489-92.

6. David TE. For everything there is a season. J Thorac Cardiovasc Surg. 2005;130: 961-5.

7. Smith CR. AATS 2012: to model excellence. J Thorac Cardiovasc Surg. 2012; 144:749-58.

8. Patterson GA. Non solus-a leadership challenge. J Thorac Cardiovasc Surg. 2010;140:495-502

9. Castaneda AR. The making of a cardiothoracic surgeon: an Appolonian quest. $J$ Thorac Cardiovasc Surg. 1994;108:806-12.

10. Loop FD. Thoracic and cardiovascular surgery. Presidential address. J Thorac Cardiovasc Surg. 1998;116:683-8.

11. Coselli JS. Competition: perspiration to inspiration. Aut inveniam viam aut faciam. J Thorac Cardiovasc Surg. 2016;152:1215-22.
12. Wallace RB. Reflections-projections! J Thorac Cardiovasc Surg. 1995;110: 1287-90.

13. Jonas RA. Rewards, risks, and responsibilities of globalization for the cardiothoracic surgeon. J Thorac Cardiovasc Surg. 2007;134:1-14.

14. del Nido PJ. Technological innovation in cardiothoracic surgery: a pragmatist's approach. J Thorac Cardiovasc Surg. 2015;150:755-61.

15. Crawford FA Jr. Thoracic surgery education — responding to a changing environment. J Thorac Cardiovasc Surg. 2003;126:1235-42.

16. Lytle BW. Who are we-who will we be? J Thorac Cardiovasc Surg. 2008;135: 965-75.

17. Cox JL. Presidential address: changing boundaries. J Thorac Cardiovasc Surg. 2001;122:413-8.

18. Schaff HV. Leadership and scholarship: unintended consequences, unexpected benefits. Available at: https://youtu.be/nPxhnAkkK4A. Accessed May 27, 2019. 